\title{
58th Denver X-ray Conference and selected papers for the special June Powder Diffraction issue
}

This special June issue of Powder Diffraction is comprised of selected papers presented at the 2009 58th Annual Denver X-ray Conference (DXC). At DXC 16 workshops, two poster sessions, and 16 special sessions were held covering the following topics: advances in detector technology; quantitative Rietveld analysis; basic XRF; specimen preparation; phase identification; trace analysis; quantitative analysis; X-ray sources/optics development; line profile analysis; structure solution; strategies for advanced materials analysis; new developments in instrumentation; environmental applications; high energy optics and high energy throughput analysis; line profile analysis; bioenabled materials; trace analysis and TXRF; X-ray imaging; materials deformation studies; stress analysis; high resolution XRD; fusion and industrial applications; and Rietveld analysis.

As part of the Denver Conference, the proceedings are published and from these proceedings, select papers covering $\mathrm{XRD}, \mathrm{XRF}$, and other high energy scattering methods were chosen for publication in Powder Diffraction. This issue of Powder Diffraction will provide the readers with the oppor- tunity to learn about current topics in a variety of materials characterization applications.

The talents of many people are required to make this special issue possible. Besides the authors themselves, we thank the manuscript reviewers John Anzelmo, Vic Buhrke, Tim Elam, John Gilfrich, Ting Huang, Jim Kaduk, Scott Misture, Cev Noyan, Robert Snyder, Brian Toby, and Rene Van Grieken. We would also like to thank The DXC conference coordinator Denise Flaherty and Powder Diffraction managing editor Nicole Ernst Boris for all of their hard work in making this publication a reality. We hope you enjoy this publication and we look forward to seeing you at the 2010 Denver X-ray Conference in Denver, Colorado on 2 to 6 August, 2010 (www.dxcicdd.com).

Tom Blanton Co-editor in Chief, Advances in X-ray Analysis Eastman Kodak Co.

George Havrilla Co-editor in Chief, Advances in X-ray Analysis Los Alamos National Laboratory

\section{Note from Editor-in-Chief}

Many thanks to the reviewers and Co-editors in Chief of Advances in X-ray Analysis (AXA) for recommending selected DXC papers for possible publication in Powder Diffraction. After being reviewed and edited by this journal, 19 of the selected AXA papers were accepted for publication in this issue, and I hope that our readers will find them interesting and useful.

Ting C. Huang

Editor-in-Chief 